\title{
Long-term effects of gastric bypass and duodenal switch on systemic exposure of atorvastatin
}

\author{
Gunn Signe Jakobsen • Ine Blankenberg Skottheim • \\ Rune Sandbu • Hege Christensen · Jo Røislien · \\ Anders Åsberg • Jøran Hjelmesæeth
}

Received: 20 July 2012/Accepted: 13 November 2012/Published online: 18 December 2012

(C) The Author(s) 2012. This article is published with open access at Springerlink.com

\begin{abstract}
Background A previous study of 22 patients undergoing either gastric bypass or duodenal switch showed increased systemic exposure of atorvastatin acid 3-8 weeks after surgery in the majority of patients. This study aimed to investigate the long-term effects on systemic exposure of atorvastatin acid in the same group of patients.

Methods An 8-h pharmacokinetic investigation was performed a median of 27 months (range 21-45 months) after surgery. Systemic exposure was measured as the area under the plasma concentration versus the time curve from 0 to $8 \mathrm{~h}$ postdose $\left(\mathrm{AUC}_{0-8}\right)$. Linear mixed models with $\mathrm{AUC}_{0-8}$ as the dependent variable were implemented to assess the effect of time, surgical procedure, and body mass index (BMI) as explanatory variables.

Results The study enrolled 20 patients. The systemic exposure of atorvastatin acid changed significantly over time $(p=0.001)$, albeit there was substantial variation between subjects. The effect of time was attenuated but remained significant after adjustment for surgical procedure and BMI $(p=0.048)$. The initial $\mathrm{AUC}_{0-8}$ increase seen in the majority of patients 3-8 weeks after surgery was normalized long term, with 7 of the 12 gastric bypass patients and 6 of the 8 duodenal switch patients showing decreased $\mathrm{AUC}_{0-8}$ compared with preoperative values.
\end{abstract}

G. S. Jakobsen ( () · R. Sandbu · J. Røislien · J. Hjelmesæth Morbid Obesity Centre, Vestfold Hospital Trust, P.O. Box 2168, 3103 Tønsberg, Norway

e-mail: gunn.signe.jakobsen@siv.no

I. B. Skottheim · H. Christensen · A. Åsberg

School of Pharmacy, University of Oslo, Oslo, Norway

J. Røislien

Department of Biostatistics, University of Oslo, Oslo, Norway
Conclusions The systemic exposure of atorvastatin showed a significant change over time after bariatric surgery, albeit with large inter- and intraindividual variations. The findings indicate that patients using atorvastatin or drugs with similar pharmacokinetic properties should be monitored closely for both therapeutic effects and adverse events the first years after gastric bypass and duodenal switch. ClinicalTrial NCT00331565.

Keywords Atorvastatin - Biliopancreatic diversion with duodenal switch · Gastric bypass - Systemic exposure

Bariatric surgery is widely used to treat morbid obesity given that it provides sustained weight loss and leads to improvement in both quality of life and obesity-related comorbidities [14, 27]. Gastric bypass and biliopancreatic diversion with duodenal switch (duodenal switch) are two commonly performed procedures [2]. Both procedures bypass the duodenum and proximal small intestine, but the bypass of the small intestine is greater with duodenal switch than with gastric bypass.

The bypass of the proximal small intestine affects the absorption of several ingested nutrients and vitamins [1]. The bioavailability of orally administered drugs also can be affected [7, 18].

We recently have shown that the systemic exposure of atorvastatin increased in the majority of patients the first weeks after both gastric bypass [29] and duodenal switch [28]. The exact mechanism for this is unknown, but we hypothesize that highly active restrictive processes in the small intestine (with regard to drug bioavailability) are bypassed, such as metabolizing enzymes in the intestinal wall. In particular, the CYP450 isoenzymes CYP3A4 and CYP3A5 are involved in restricting the bioavailability of 
atorvastatin and many other substrate drugs [21]. These CYP enzymes are highly expressed in the proximal intestine and decrease along the small intestine [20].

Patients normally lose weight quickly after bariatric surgery. This process often continues for the first 2 years postoperatively, after which the weight either stabilizes or takes the shape of a small long-term weight gain. No conclusive explanations exist to elucidate why the weight loss stops, but it might partly be explained by adaptive changes in the intestine, changed habits of the patients, or metabolic adaptation [10]. Similar mechanisms also may affect drug bioavailability.

In this study, we aimed to explore possible long-term adaptive changes in the systemic exposure of atorvastatin in patients previously treated with either gastric bypass or duodenal switch [28, 29].

\section{Materials and methods}

We have previously presented the short-term results of this prospective, open, controlled, nonrandomized, singlecenter study that investigated 22 patients listed for either gastric bypass $(n=12)$ or duodenal switch $(n=10)$ [28, 29]. Pharmacokinetic investigations of atorvastatin acid were performed the day before bariatric surgery (baseline) and repeated in the early postoperative phase (3-8 weeks) (short-term follow-up evaluation).

In the current study, a third pharmacokinetic investigation was performed to assess the long-term effects of the two bariatric procedures on systemic exposure of atorvastatin acid. All patients giving specific informed consent for this long-term follow-up investigation were included in the study.

The inclusion and exclusion criteria have been presented previously [28, 29]. Briefly, adult morbidly obese patients [body mass index (BMI) $\geq 40 \mathrm{~kg} / \mathrm{m}^{2}$ or BMI $\geq 35 \mathrm{~kg} / \mathrm{m}^{2}$ combined with comorbidity] assigned to undergo either gastric bypass or duodenal switch were included in the study. Additional surgery that could potentially interfere with drug bioavailability was an exclusion criterion for the long-term follow-up study. Patients treated with substances that could affect the pharmacokinetics of atorvastatin (listed in previous publications [28, 29]) were not eligible for inclusion in the study.

All the patients were treated with statins on clinical indication before surgery. Patients who used other types of statins were switched to atorvastatin (Lipitor). At both baseline and short- and long-term follow-up evaluations, all the patients received the same dose of atorvastatin for at least 14 days to be in steady-state condition at the time of the investigations. In addition, they completed a drug diary. If a patient had withdrawn from statin treatment or changed the dose since the last investigation, he or she was reintroduced to the same dose of atorvastatin given each morning 2 weeks before the investigation.

The study was conducted in accordance with international and national laws and guidelines. Approvals were obtained from the regional ethics committee and all relevant Norwegian authorities. The study is registered at ClinicalTrial NCT00331565.

\section{Outcome}

The primary outcome was the change in systemic exposure of atorvastatin acid, assessed by the area under the plasma concentration versus the time curve from 0 to $8 \mathrm{~h}$ postdose $\left(\mathrm{AUC}_{0-8}\right)$ from baseline (before surgery) via short-term (3-8 weeks) to long-term (21-45 months) follow-up evaluation. Changes in maximal concentration $\left(C_{\max }\right)$ and time to reach $C_{\max }\left(\mathrm{t}_{\max }\right)$ for atorvastatin acid also were assessed. The main explanatory variables were time after surgery, surgical procedure, and BMI.

\section{Surgical procedures}

The surgical procedure used was either laparoscopic gastric bypass or biliopancreatic diversion with duodenal switch. Detailed descriptions of the procedures have been presented elsewhere [13, 28, 29]. In short, the gastric bypass was performed by making a small gastric pouch, an $80 \mathrm{~cm}$ biliopancreatic limb, and a $120 \mathrm{~cm}$ alimentary limb. The remaining part (not measured) of the small intestine is the common channel in which food is mixed with gastric, bile, and pancreatic juices (Fig. 1).

The duodenal switch included a vertical sleeve gastrectomy preserving a normal pyloric function. The jejunum was fully bypassed, and an anastomosis was made between the duodenum (proximal to the papilla Vateri) and the small intestine $2.5 \mathrm{~m}$ from the ileocecal valve. The entero-enteroanastomosis was made $1 \mathrm{~m}$ from the ileocoecal valve so that food was exposed to bile and pancreatic juice only in the last $100 \mathrm{~cm}$ of the ileum, the common channel (Fig. 2).

\section{Pharmacokinetics and bioanalysis}

A 24-h pharmacokinetic investigation was performed the day before bariatric surgery (baseline), followed by an $8 \mathrm{~h}$ pharmacokinetic investigation short term (3-8 weeks) after surgery as previously reported [28, 29]. In this study, an additional 8-h pharmacokinetic investigation was conducted long term ( $>21$ months) after surgery. As a part of this pharmacokinetic investigation, patients reported to the hospital after an overnight fast (water was permitted but no food, drugs, nicotine, or caffeine). A standard hospital 


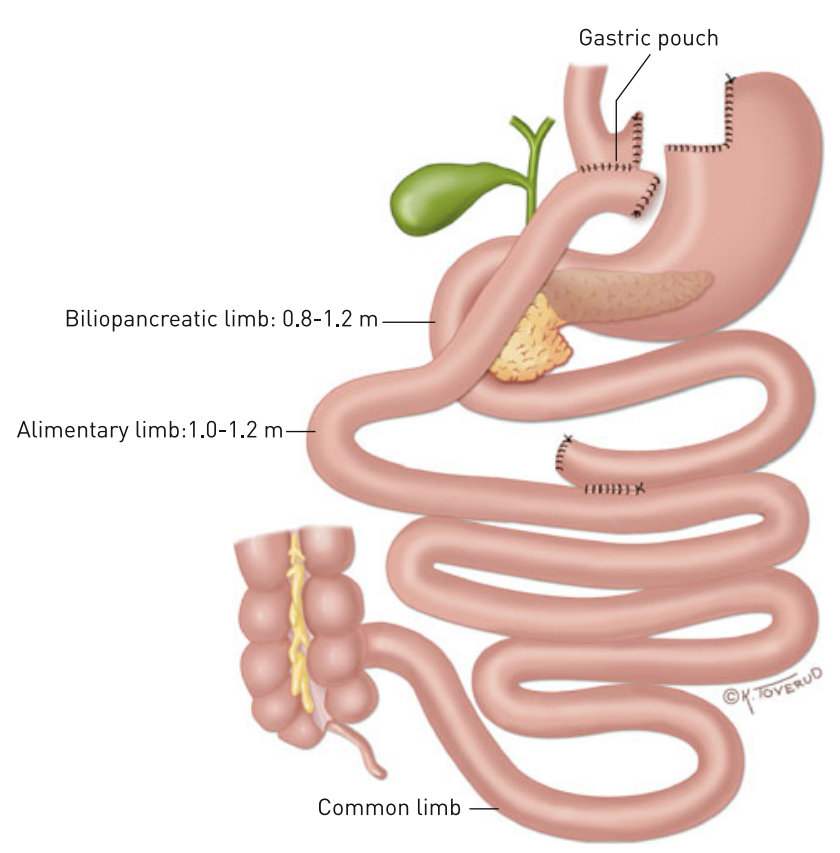

Fig. 1 Gastric bypass. By Kari C. Toverud (reproduced from reference [13])

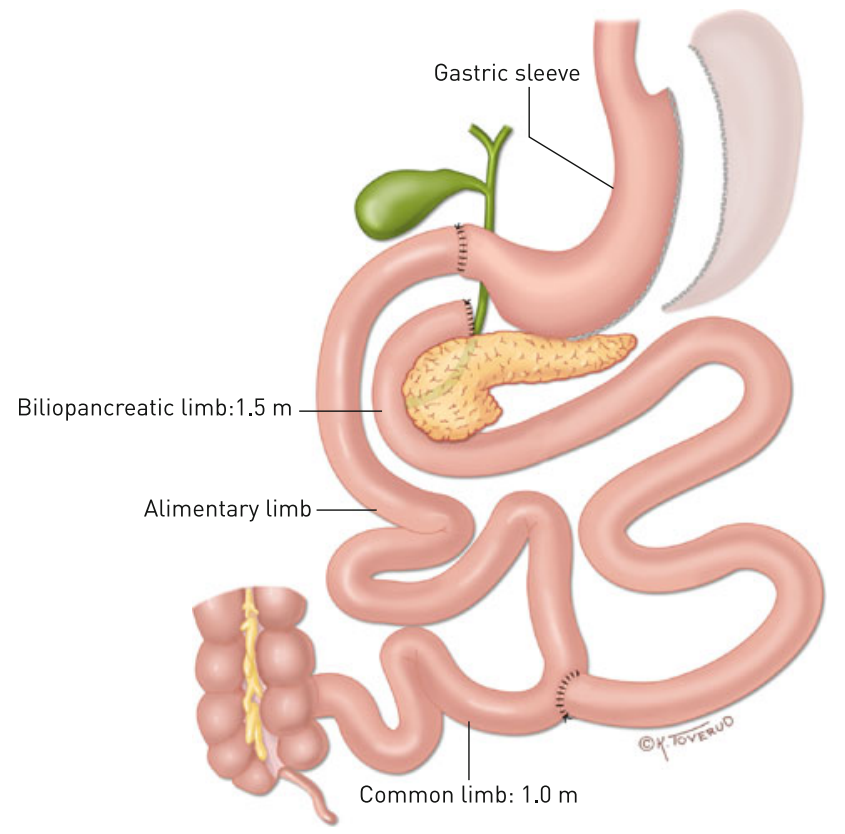

Fig. 2 Biliopancreatic diversion with duodenal switch. By Kari C. Toverud (reproduced from reference [13])

breakfast was served 2-h after atorvastatin administration, and there were no food restrictions thereafter. Concomitant drugs ordinarily administered in the morning were given at breakfast.

Blood samples for the determination of plasma atorvastatin concentrations were drawn in prechilled heparin vacutainers, kept on ice, and centrifuged at $1,800 \mathrm{~g}$ at $4{ }^{\circ} \mathrm{C}$ for $10 \mathrm{~min}$, after which plasma was decanted and stored at $-80{ }^{\circ} \mathrm{C}$ within $1 \mathrm{~h}$ of sampling. Blood samples were drawn at predose, then $0.5,1,1.5,2,3,5,6$, and $8 \mathrm{~h}$ after atorvastatin administration for all investigations.

Atorvastatin acid was analyzed with a validated highperformance liquid chromatography method using tandem mass spectrometry detection [12, 29]. Briefly, sample preparation was performed by solid-phase extraction on $\mathrm{C}_{18}$ cartridges followed by chromatographic separation on a $\mathrm{C}_{18}$ analytical column combined with electrospray tandem mass spectrometric detection.

Noncompartmental analyses of pharmacokinetic variables were performed using the actual measured values for $C_{\max }$ and $t_{\max }$. The $\mathrm{AUC}_{0-8}$ was calculated using the trapezoidal method in Microsoft Office Excel 2007 (Microsoft, Redmond, WA, USA) [29].

Statistical analyses

Data are presented as mean \pm standard deviation unless stated otherwise. The dependent variables all were skewly distributed and log-transformed before statistical analysis. To assess the association of time, surgical procedure, and BMI with the changes in systemic exposure of atorvastatin acid, we fitted two linear mixed models with AUC as the dependent variable: a crude model with time as the only explanatory variable and an adjusted model with time, surgical procedure, BMI, and the interaction between time and surgical procedure as explanatory variables. All $p$ values lower than 0.05 were considered statistically significant. Statistical analyses were performed using SPSS version 16.0 (SPSS, Inc., Chicago, IL, USA) and R 2.12 [23].

\section{Results}

All 12 patients (six women) in the gastric bypass group were examined three times: at baseline (the day before surgery) and at short-term (3-8 weeks after surgery) and long-term (21-39 months after surgery) follow-up evaluation. All 10 patients (five women) in the duodenal switch group were examined two times; at baseline and at shortterm follow-up evaluation.

After the exclusion of one patient due to reoperation that altered the lengths of the intestinal limbs and one patient who declined to participate, eight duodenal switch patients ( 4 women) were included in the long-term follow-up study. The median follow-up time was 25 months (range 23-45 months) after the duodenal switch and 27 months (range, 21-45 months) for all the patients. All the patients were Caucasians. Only 8 of the 20 patients were continuing to receive statin treatment at the time of inclusion for the 
long-term follow-up measurement, with four patients using atorvastatin and four patients using simvastatin. The patient characteristics at baseline and at the last follow-up assessment are shown in Table 1 .

The systemic exposure of atorvastatin acid varied substantially between the patients (Fig. 3; Table 4) and changed significantly over time (Table 2, crude model; $p=0.001)$. The effect of time was attenuated but remained significant after adjustment for surgical procedure and BMI (Table 2). Furthermore, the surgical procedure times time interaction term was nonsignificant $(p=0.221)$.

Although the systemic exposure of atorvastatin acid varied substantially, 7 of the 12 gastric bypass patients and 6 of the 8 duodenal switch patients showed a decreased $\mathrm{AUC}_{0-8}$ long term compared with before surgery (Table 4). The mean long-term/baseline ratio of atorvastatin acid $\mathrm{AUC}_{0-8}$ was $0.8 \pm 0.5$ compared with the short-term/ baseline ratio of $1.6 \pm 0.9$ (Table 3 ).

The $C_{\max }$ values for atorvastatin acid showed the same trend as the $\mathrm{AUC}_{0-8}$ values in the long term (mixed model: $p=0.012$; estimate, $-0.017 ; 95 \%$ confidence interval -0.03 to -0.00$)$. On the other hand, $T_{\max }$ increased with time, from $1.4 \pm 1.2$ to $2.8 \pm 1.9 \mathrm{~h}$ (mixed model: $p=0.002$; estimate, $0.02 ; 95 \%$ confidence interval -0.01 to -0.04 ) (Tables 3, 4).

\section{Discussion}

The current prospective study of patients undergoing bariatric surgery shows a significant change in atorvastatin systemic exposure over time. Although large interindividual variations may limit the generalizability of the study, the long-term results show that the initial increase in atorvastatin systemic exposure observed in the majority of patients 3 to 8 weeks after surgery was reversed approximately 2 years after surgery. The majority of patients actually showed a lower atorvastatin systemic exposure long term compared with baseline (Fig. 3; Table 4). Our study emphasizes time after bariatric surgery as an

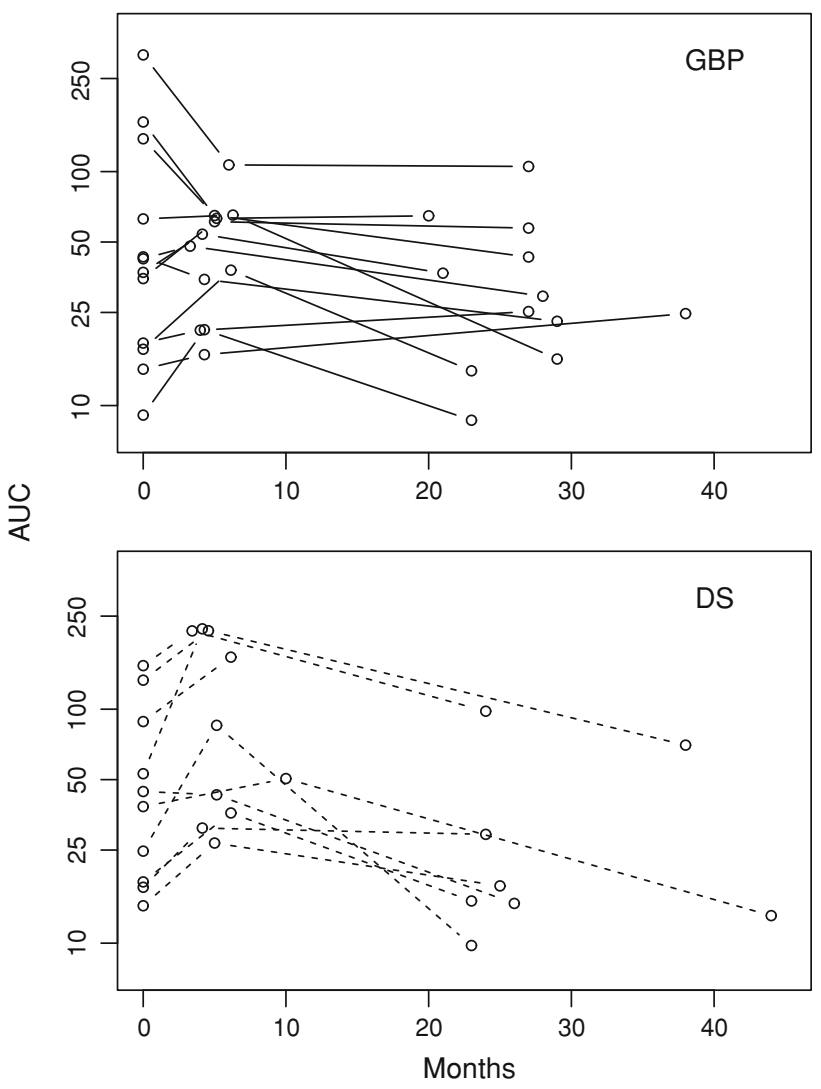

Fig. 3 Individual atorvastatin acid $\mathrm{AUC}_{0-8}(\mathrm{ng} \mathrm{h} / \mathrm{mL})$ preoperatively and at both short- and long-term follow-up evaluation. $\mathrm{AUC}_{0-8}$, area under the plasma concentration versus the time curve from 0 to $8 \mathrm{~h}$ postdose; GBP, gastric bypass; DS, duodenal switch

important factor to be considered with regard to systemic drug exposure in these patients.

Few studies have evaluated the effect of current bariatric procedures on systemic drug exposure [7]. To our knowledge, the current study is the first to examine changes in systemic exposure of drugs after biliopancreatic diversion with duodenal switch. Furthermore, the effect of different bariatric procedures on systemic exposure of equivalent drugs was not investigated in the same trial earlier.
Table 1 Patient demographics, body mass index (BMI), and comorbidities
Data are given as mean \pm standard deviation or as the number of patients

OSA obstructive sleep apnea

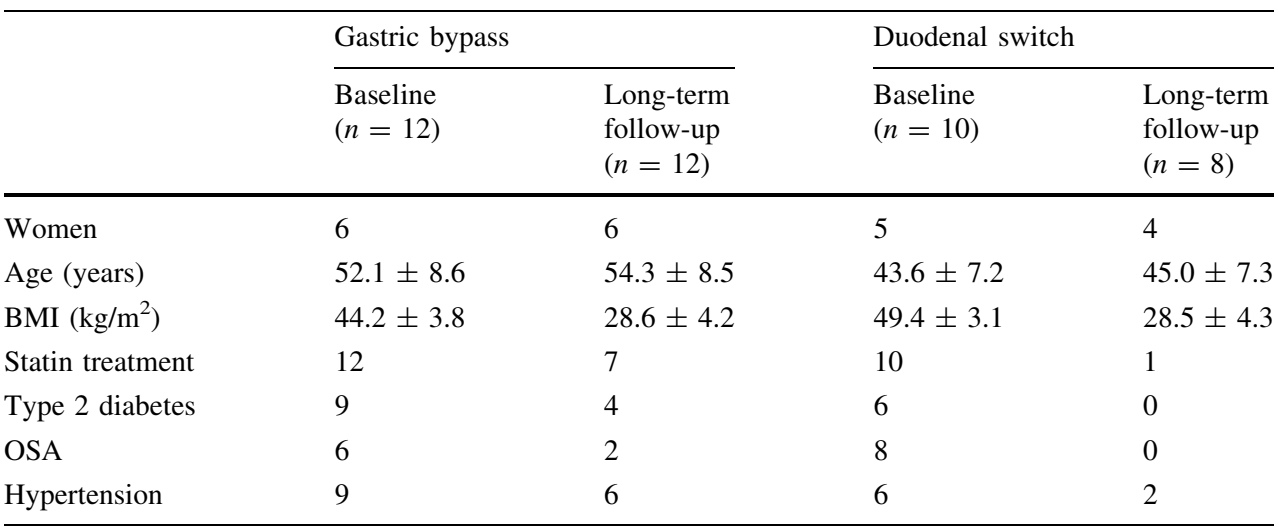


Table 2 Systemic exposure $\left(\mathrm{AUC}_{0-8}\right)$ of atorvastatin acid, effect of time, surgical procedure, and body mass index (BMI)

\begin{tabular}{|c|c|c|c|c|}
\hline \multirow[b]{2}{*}{ Explanatory variable } & \multicolumn{2}{|l|}{ Crude model } & \multicolumn{2}{|l|}{ Adjusted model } \\
\hline & Estimate $(95 \% \mathrm{CI})$ & $p$ value & Estimate $(95 \% \mathrm{CI})$ & $p$ value \\
\hline Time & $-0.018(-0.028$ to -0.008$)$ & 0.001 & $-0.024(-0.046$ to -0.001$)$ & 0.048 \\
\hline Surgical procedure & & & $0.418(-0.289$ to 1.125$)$ & 0.260 \\
\hline Surgical procedure $\times$ time & & & $-0.013(-0.034$ to 0.007$)$ & 0.221 \\
\hline BMI & & & $-0.021(-0.055$ to 0.013$)$ & 0.239 \\
\hline
\end{tabular}

Linear mixed model analysis

$C I$ confidence interval, $A U C_{0-8}$ area under the plasma concentration versus the time curve from 0 to $8 \mathrm{~h}$ postdose

Table 3 Pharmacokinetic parameters of atorvastatin acid

\begin{tabular}{lcll}
\hline & Baseline & $\begin{array}{l}\text { Ratio short } \\
\text { term/baseline }\end{array}$ & $\begin{array}{l}\text { Ratio long } \\
\text { term/baseline }\end{array}$ \\
\hline AUC $(\mathrm{ng} * \mathrm{~h} / \mathrm{mL})$ & $67.4(73.4)$ & $1.6(0.9)$ & $0.8(0.5)$ \\
$C_{\max }(\mathrm{ng} / \mathrm{mL})$ & $24.5(37.2)$ & $1.7(1.4)$ & $0.9(0.6)$ \\
$T_{\max }(\mathrm{h})$ & $1.4(1.2)$ & $2.2(1.8)$ & $2.9(3.1)$ \\
\hline
\end{tabular}

Data are given as mean \pm standard deviation. Ratios are calculated with short- or long-term values (numerators) and with values at baseline (before surgery) as denominators

$A U C$ area under the plasma concentration versus the time curve, $C_{\max }$ maximum plasma concentration, $T_{\max }$ time to reach $C_{\max }$

In a recent prospective study, Hamad et al. [11] performed repeated measures of drug exposure levels in 12 patients using five different serotonin reuptake inhibitors, both before gastric bypass and three times during the first postoperative year. Most of the patients (8/12) showed a reduced drug AUC 1 month after surgery and normalization to preoperative values after 1 year. This pattern of an initial acute change in exposure levels followed by a return to baseline mirrors the results in the current study.

The opposite direction of the acute change in systemic exposure probably is explained by different properties of the drugs investigated in the respective trials. The antidepressants investigated are mainly metabolized by CYP2D6 and CYP2C19, which represent only a minor portion of the intestinal CYP content [22]. Consequently, these drugs are not metabolized to any relevant degree in the intestinal mucosa. In this situation, a change in absorptive surface area seems to be the most likely explanation for the findings.

On the other hand, atorvastatin is subjected to CYP3A metabolism, which is a major component of the intestinal metabolizing capacity [22]. Hence, bypassing intestinal segments rich in CYP3A enzymes reduces both the intestinal first-pass metabolism and the absorptive surface area. The net result might be an increased systemic exposure due to the outweighing effect of reduced intestinal enzymatic capacity.

Cross-sectional studies of immunosuppressants [25], metformin [19], moxifloxacin [3], sertraline [24], and thyroxine [26] variously report reduced, increased, and unchanged systemic exposure 2 months to 7 years after gastric bypass. The diversity of the findings underscores the importance of properly designed clinical trials. In addition, it indicates that therapeutic effects must be evaluated or serum concentrations measured for each patient postoperatively.

The observed long-term normalization of systemic exposure of atorvastatin acid in the current study may be due to an intestinal adaptation (e.g., by upregulation of CYP3A4) in the small intestine that is more proximally sited after the operations. Investigations after reoperations of obsolete bariatric surgical procedures have shown long-term changes in both enzymatic activity (increased activity of lactase, sucrase, alkaline phosphatase, and thymidine kinase) and morphologic parameters (increased length of intestinal segments and villous hypertrophy) [4, 6, 8, 31, 32].

Adaptation of the intestine also may affect drug bioavailability. Two recent studies have addressed mucosal function and adaptation after gastric bypass. A significant decrease in villous surface area and increased cell proliferation with time was reported in jejunal mucosa just distal to the gastric pouch in eight patients 6 to 8 months after gastric bypass [30]. The authors interpreted these changes as an adaptation of the jejunal mucosa to an appearance more suited for food reception and tissue defense.

Increased cell proliferation in rats that underwent gastric bypass also were shown by le Roux et al. [15]. Additionally, in both rats and humans, they showed dynamic changes in the postprandial rise in glucagon-like peptide-2, a hormone that has a direct effect on bowel mucosa and increases the absorptive surface [5], with a peak at 6 months postoperatively and normalization to preoperative levels at 24 months. This accords with our finding of a long-term dynamic change in systemic exposure of atorvastatin after gastric bypass and duodenal switch.

It has been increasingly evident that CYP3A expression and activity are regulated by nongenetic factors such as endogenous and exogenous chemicals, including steroids 
Table 4 Atorvastatin acid pharmacokinetic parameters

\begin{tabular}{|c|c|c|c|c|c|c|c|c|c|}
\hline \multirow[b]{2}{*}{ Patient } & \multicolumn{3}{|c|}{$\mathrm{AUC}_{0-8}(\mathrm{ng} * \mathrm{~h} / \mathrm{mL})$} & \multicolumn{3}{|c|}{$C_{\max }(\mathrm{ng} / \mathrm{mL})$} & \multicolumn{3}{|l|}{$\mathrm{T}_{\max }(\mathrm{h})$} \\
\hline & Baseline & $\begin{array}{l}\text { Ratio short } \\
\text { term/baseline }\end{array}$ & $\begin{array}{l}\text { Ratio long } \\
\text { term/baseline }\end{array}$ & Baseline & $\begin{array}{l}\text { Ratio short } \\
\text { term/baseline }\end{array}$ & $\begin{array}{l}\text { Ratio long } \\
\text { term/baseline }\end{array}$ & Baseline & $\begin{array}{l}\text { Ratio short } \\
\text { term/baseline }\end{array}$ & $\begin{array}{l}\text { Ratio long } \\
\text { term/baseline }\end{array}$ \\
\hline \multicolumn{10}{|c|}{ Gastric bypass } \\
\hline 9 & 9 & 2.3 & 1.0 & 2.3 & 2.0 & 0.8 & 1.1 & 2.7 & 2.6 \\
\hline 10 & 14 & 1.2 & 1.7 & 5.3 & 0.7 & 1.8 & 0.6 & 0.8 & 4.9 \\
\hline 8 & 17 & 2.2 & 0.8 & 4.0 & 2.2 & 1.0 & 2.7 & 0.2 & 1.1 \\
\hline 7 & 19 & 1.1 & 1.4 & 5.0 & 0.7 & 1.3 & 0.7 & 1.7 & 4.5 \\
\hline 5 & 35 & 1.8 & 1.6 & 5.7 & 3.0 & 1.8 & 5.9 & 0.3 & 1.0 \\
\hline 12 & 37 & 1.5 & 1.0 & 8.7 & 1.3 & 0.8 & 1.1 & 2.7 & 2.7 \\
\hline 3 & 42 & 1.1 & 0.7 & 7.6 & 1.6 & 1.5 & 0.8 & 3.8 & 3.8 \\
\hline 2 & 43 & 0.8 & 0.5 & 7.1 & 1.0 & 0.8 & 1.0 & 0.8 & 0.6 \\
\hline 1 & 63 & 1.0 & 0.3 & 10.5 & 1.5 & 0.3 & 1.3 & 2.5 & 3.9 \\
\hline 6 & 138 & 0.5 & 0.3 & 33.0 & 0.6 & 0.4 & 1.0 & 0.5 & 2.4 \\
\hline 11 & 163 & 0.4 & 0.4 & 117.4 & 0.2 & 0.2 & 1.0 & 1.5 & 2.8 \\
\hline 4 & 315 & 0.3 & 0.3 & 133.7 & 0.2 & 0.4 & 1.6 & 1.9 & 0.7 \\
\hline Mean \pm SD & $74 \pm 90$ & $1.2 \pm 0.7$ & $0.8 \pm 0.5$ & $28 \pm 46$ & $1.3 \pm 0.8$ & $0.9 \pm 0.6$ & $1.6 \pm 1.5$ & $1.6 \pm 1.1$ & $2.6 \pm 1.5$ \\
\hline \multicolumn{10}{|c|}{ Duodenal switch } \\
\hline 3 & 14 & 1.9 & 1.2 & 3.9 & 1.5 & 1.2 & 0.9 & 3.4 & 1.1 \\
\hline 4 & 17 & 1.8 & 1.7 & 2.8 & 2.3 & 2.1 & 2.5 & 0.8 & 0.3 \\
\hline 8 & 18 & 2.0 & 0.8 & 3.1 & 2.6 & 1.5 & 1.8 & 0.3 & 0.5 \\
\hline 10 & 25 & 3.4 & 0.4 & 6.3 & 6.2 & 0.4 & 0.6 & 5.5 & 1.8 \\
\hline 5 & 38 & 1.3 & 0.3 & 7.8 & 1.8 & 0.3 & 0.6 & 5.6 & 14.5 \\
\hline 1 & 44 & 1.0 & 0.3 & 15.9 & 0.5 & 0.3 & 0.6 & 3.6 & 2.5 \\
\hline 2 & 53 & 4.2 & ND & 13.5 & 4.2 & ND & 0.5 & 6.0 & ND \\
\hline 6 & 89 & 1.9 & ND & 24.2 & 1.6 & ND & 2.4 & 1.3 & ND \\
\hline 9 & 133 & 1.6 & 0.5 & 42.6 & 1.0 & 0.4 & 0.5 & 1.3 & 4.1 \\
\hline 7 & 153 & 1.4 & 0.6 & 78.5 & 0.8 & 0.2 & 1.4 & 2.2 & 3.5 \\
\hline Mean \pm SD & $59 \pm 59$ & $2.0 \pm 1.0$ & $0.7 \pm 0.5$ & $20 \pm 24$ & $2.2 \pm 1.7$ & $0.8 \pm 0.7$ & $1.2 \pm 0.8$ & $3.0 \pm 2.1$ & $3.5 \pm 4.7$ \\
\hline
\end{tabular}

$A U C_{0-8}$ area under the plasma concentration versus the time curve from 0 to $8 \mathrm{~h}$ postdose, $C_{\max }$ maximum plasma concentration, $T_{\max }$ time to reach $\mathrm{C}_{\max }, S D$ standard deviation, $N D$ Not Done

and xenobiotics as well as disease states involving cytokines [17, 33]. Accordingly, CYP3A intestinal adaptation may be a possible explanation for the normalization of systemic exposure of atorvastatin acid in the current study.

Our findings may have several other explanations including physiologic changes after bariatric surgery affecting drug bioavailability. The surgery induces a substantial weight loss long term and affects the serum levels of gastrointestinal and systemic hormones [16]. Previous studies also have shown that body weight is associated with intestinal CYP3A activity, and it is conceivable that substantial weight loss after bariatric surgery may induce an increase in CYP3A protein expression over time [9]. In addition, bypassing the small intestine may affect the impact of drug transporters and metabolizing enzymes other than CYP3A on drug bioavailability.

Most of the patients investigated in this study showed changes in systemic exposure of atorvastatin that might be clinically relevant regarding both efficacy and adverse effects. It is conceivable that the results may be extrapolated to other drugs primarily metabolized by CYP3A such as immunosuppressives, calcium-channel blockers, and some antiepileptics, but clinical trials to test each situation are necessary. In addition, the clinical consequences of changes in the systemic exposure of other drugs may differ from those of atorvastatin and therefore warrant close monitoring of patients. For drugs more extensively metabolized by CYP3A, the magnitude of change in systemic exposure might be even greater.

A major limitation of the current study was the relatively small sample size. Nevertheless, to the best of our knowledge, this is the first prospective study to investigate systemic drug exposure in detail more than 1 year after surgery and after two different bariatric surgical procedures. Each patient acted as his or her own control, which directly addressed the changes in systemic exposure after 
gastric bypass or duodenal switch for the individual across time. Importantly, our results should be considered as hypothesis generating and as requiring verification.

The current study has shown a significant change over time in the systemic exposure of atorvastatin after gastric bypass and duodenal switch, albeit with large inter- and intraindividual variations. Our findings indicate that patients using atorvastatin or drugs with similar pharmacokinetic properties should be monitored closely for both therapeutic and adverse effects, particularly in the case of narrow therapeutic windows. Accordingly, repeated drug dose adjustment may be necessary during the first years after gastric bypass and duodenal switch.

Acknowledgments We thank Linda Mathisen for her assistance with logistics and Matthew McGee for proofreading the manuscript.

Disclosures Gunn Signe Jakobsen, Ine Blankenberg Skottheim, Rune Sandbu, Hege Christensen, Jo Røislien, Anders Åsberg, and Jøran Hjelmesæth have no conflicts of interest or financial ties to disclose. Gunn Signe Jakobsen has received an unrestricted educational grant from Vestfold Hospital Trust.

Open Access This article is distributed under the terms of the Creative Commons Attribution License which permits any use, distribution, and reproduction in any medium, provided the original author(s) and the source are credited.

\section{References}

1. Aasheim ET, Bjorkman S, Sovik TT, Engstrom M, Hanvold SE, Mala T, Olbers T, Bohmer T (2009) Vitamin status after bariatric surgery: a randomized study of gastric bypass and duodenal switch. Am J Clin Nutr 90:15-22

2. Buchwald H, Oien D (2009) Metabolic/bariatric surgery worldwide 2008. Obes Surg 19:1605-1611

3. De Smet J, Colin P, De Paepe P, Ruige J, Batens H, Van Nieuwenhove Y, Vogelaers D, Blot S, Van Bocxlaer J, Van Bortel LM, Boussery K (2012) Oral bioavailability of moxifloxacin after Roux-en-Y gastric bypass surgery. J Antimicrob Chemother 67: 226-229

4. Drozdowski LA, Clandinin MT, Thomson AB (2009) Morphological, kinetic, membrane biochemical, and genetic aspects of intestinal enteroplasticity. World J Gastroenterol 15:774-787

5. Drucker DJ (2003) Glucagon-like peptides: regulators of cell proliferation, differentiation, and apoptosis. Mol Endocrinol 17:161-171

6. Dudrick SJ, Daly JM, Castro G, Akhtar M (1997) Gastrointestinal adaptation following small bowel bypass for obesity. Ann Surg 185:642-648

7. Edwards A, Ensom MH (2012) Pharmacokinetic effects of bariatric surgery. Ann Pharmacother 46:130-136

8. Fenyo G, Backman L, Hallberg D (1976) Morphological changes of the small intestine following jejuno-ileal shunt in obese subjects. Acta Chir Scand 142:154-159

9. Greenblatt DJ, Abernethy DR, Locniskar A, Harmatz JS, Limjuco RA, Shader RI (1984) Effect of age, gender, and obesity on midazolam kinetics. Anesthesiology 61:27-35

10. Hall KD (2010) Predicting metabolic adaptation, body weight change, and energy intake in humans. Am J Physiol Endocrinol Metab 298:E449-E466
11. Hamad GG, Helsel JC, Perel JM, Kozak GM, McShea MC, Hughes C, Confer AL, Sit DK, McCloskey CA, Wisner KL (2012) The effect of gastric bypass on the pharmacokinetics of serotonin reuptake inhibitors. Am J Psychiatry 169:256-263

12. Hermann M, Christensen H, Reubsaet JL (2005) Determination of atorvastatin and metabolites in human plasma with solid-phase extraction followed by LC-tandem MS. Anal Bioanal Chem 382:1242-1249

13. Hofso D, Aasheim ET, Sovik TT, Jakobsen GS, Johnson LK, Sandbu R, Aas AT, Kristinsson J, Hjelmesaeth J (2011) Follow-up after bariatric surgery. Tidsskr Nor Laegeforen 131:1887-1892

14. Karlsson J, Taft C, Ryden A, Sjostrom L, Sullivan M (2007) Tenyear trends in health-related quality of life after surgical and conventional treatment for severe obesity: the SOS intervention study. Int J Obes London 31:1248-1261

15. le Roux CW, Borg C, Wallis K, Vincent RP, Bueter M, Goodlad R, Ghatei MA, Patel A, Bloom SR, Aylwin SJ (2010) Gut hypertrophy after gastric bypass is associated with increased glucagon-like peptide 2 and intestinal crypt cell proliferation. Ann Surg 252:50-56

16. Michalakis K, le Roux C (2012) Gut hormones and leptin: impact on energy control and changes after bariatric surgery: what the future holds. Obes Surg 22:1648-1657

17. Morgan ET, Goralski KB, Piquette-Miller M, Renton KW, Robertson GR, Chaluvadi MR, Charles KA, Clarke SJ, Kacevska M, Liddle C, Richardson TA, Sharma R, Sinal CJ (2008) Regulation of drug-metabolizing enzymes and transporters in infection, inflammation, and cancer. Drug Metab Dispos 36:205-216

18. Padwal R, Brocks D, Sharma AM (2010) A systematic review of drug absorption following bariatric surgery and its theoretical implications. Obes Rev 11:41-50

19. Padwal RS, Gabr RQ, Sharma AM, Langkaas LA, Birch DW, Karmali S, Brocks DR (2011) Effect of gastric bypass surgery on the absorption and bioavailability of metformin. Diabetes Care 34:1295-1300

20. Paine MF, Khalighi M, Fisher JM, Shen DD, Kunze KL, Marsh CL, Perkins JD, Thummel KE (1997) Characterization of interintestinal and intraintestinal variations in human CYP3A-dependent metabolism. J Pharmacol Exp Ther 283:1552-1562

21. Paine MF, Shen DD, Kunze KL, Perkins JD, Marsh CL, McVicar JP, Barr DM, Gillies BS, Thummel KE (1996) First-pass metabolism of midazolam by the human intestine. Clin Pharmacol Ther 60:14-24

22. Paine MF, Hart HL, Ludington SS, Haining RL, Rettie AE, Zeldin DC (2006) The human intestinal cytochrome P450 "pie". Drug Metab Dispos 34:880-886

23. R Development Core Team (2008) R: A language and environment for statistical computing. R Foundation for Statistical Computing, Vienna, Austria. ISBN 900051-07-0. http://www.R-project.org

24. Roerig JL, Steffen K, Zimmerman C, Mitchell JE, Crosby RD, Cao L (2012) Preliminary comparison of sertraline levels in postbariatric surgery patients versus matched nonsurgical cohort. Surg Obes Relat Dis 8:62-66

25. Rogers CC, Alloway RR, Alexander JW, Cardi M, Trofe J, Vinks AA (2008) Pharmacokinetics of mycophenolic acid, tacrolimus and sirolimus after gastric bypass surgery in end-stage renal disease and transplant patients: a pilot study. Clin Transpl 22:281-291

26. Rubio I, Galrão A, Santo M, Zanini A, Medeiros-Neto G (2012) Levothyroxine absorption in morbidly obese patients before and after Roux-en-Y gastric bypass (RYGB) surgery. Obes Surg 22:253-258

27. Sjostrom L, Lindroos AK, Peltonen M, Torgerson J, Bouchard C, Carlsson B, Dahlgren S, Larsson B, Narbro K, Sjostrom CD, Sullivan M, Wedel H (2004) Lifestyle, diabetes, and cardiovascular risk factors 10 years after bariatric surgery. N Engl J Med 351:2683-2693 
28. Skottheim IB, Jakobsen GS, Stormark K, Christensen H, Hjelmesaeth J, Jenssen T, Asberg A, Sandbu R (2010) Significant increase in systemic exposure of atorvastatin after biliopancreatic diversion with duodenal switch. Clin Pharmacol Ther 87:699-705

29. Skottheim IB, Stormark K, Christensen H, Jakobsen GS, Hjelmesaeth J, Jenssen T, Reubsaet JL, Sandbu R, Asberg A (2009) Significantly altered systemic exposure to atorvastatin acid following gastric bypass surgery in morbidly obese patients. Clin Pharmacol Ther 86:311-318

30. Spak E, Björklund P, Helander HF, Vieth M, Olbers T, Casselbrant A, Lönroth H, Fändriks L (2010) Changes in the mucosa of the Roux limb after gastric bypass surgery. Histopathology 57:680-688
31. Stein TA, Wise L (1978) Functional adaptation of the intestinal mucosal enzymes after jejunoileal bypass for morbid obesity. Am J Clin Nutr 31:1143-1148

32. Stock-Damge C, Aprahamian M, Raul F, Marescaux J, Scopinaro N (1986) Small-intestinal and colonic changes after biliopancreatic bypass for morbid obesity. Scand J Gastroenterol 21: 1115-1123

33. Takeshita A, Taguchi M, Koibuchi N, Ozawa Y (2002) Putative role of the orphan nuclear receptor SXR (steroid and xenobiotic receptor) in the mechanism of CYP3A4 inhibition by xenobiotics. J Biol Chem 277:32453-32458 